\title{
Optimized Antiretroviral Therapy with Darunavir/Ritonavir, Etravirine and/or Raltegarvir: A Salvage Therapy Option in HIV-1 Infected Patients with Long-Term Therapeutic Failures, about 23 Cases*
}

\author{
Vincent Guiyedi ${ }^{1,2,3 \#}$, Olivier Mounoury ${ }^{4}$, Soraya Boucherit ${ }^{1,2}$, Pascale Longuet ${ }^{2}$, C. Brunet-François ${ }^{4}$, \\ Eric Kendjo $^{5,6}$, J. L. Ecobichon ${ }^{1,2}$, Madeleine Okome-Nkoumou ${ }^{3}$, Catherine Leport ${ }^{1,2}$, F. Raffi $^{4}$ \\ ${ }^{1}$ Laboratoire de Recherche en Pathologie Infectieuse, Université Diderot-Paris, Paris, France; ${ }^{2}$ Service des Maladies Infectieuses et \\ Tropicales, CHU Xavier BICHAT, APHP, Paris, France; ${ }^{3}$ Departement de Maladies Infectieuses et Tropicales, Faculté de Médecine \\ de Libreville, Université des Sciences de la Santé, Libreville, Gabon; ${ }^{4}$ Service des Maladies Infectieuses et Tropicales, Hotel Dieu, \\ CHU Nantes, France; ${ }^{5}$ Centre Nationale de Référence du Paludisme, UPMC, InVS, Paris, France; ${ }^{6}$ Department of Parasitology, In- \\ stitute of Tropical Medicine, University of Tübingen, Tübingen, Germany. \\ Email: "guidyvin@hotmail.com
}

Received August $7^{\text {th }}, 2012$; revised September $13^{\text {th }}, 2012$; accepted September $23^{\text {rd }}, 2012$

\begin{abstract}
Objectives: The aims of this study was to analyze the immuno-virologic response after optimised background antiretroviral therapy (OBT) associated to new active antiretroviral treatment (ART) in HIV-1 infected patients with chronic virologic failure. Methods: We conduced a descriptive analysis of the immuno-virologic responses in HIV-1 adult infected patients: 1) harbouring multiple therapeutic failures with ART; 2) with no virologic response obtained over 10 years (1997-2008); and 3) treated with OBT combined with new drugs including at least 1 of the 3 active ART among darunavir/ritonavir, etravirine and raltegravir; 4) observed between month 0 (M0), before new ART to month 12 (M12) after new ART initialisation. Results: Twenty three patients were included in the study. After OBT, the proportion of patients with undetectable viral load was significantly higher at M6 and M12 than M0 (86\% and 73\% versus $0 \%$, p = 0.03 , respectively). At the same period, the median HIV viral load decreased significantly in 19/23 (83\%) patients from 4.3 to $1.69 \log _{10}$ HIV-1 RNA copies/ml ( $<<0.001$, respectively). The median CD4-T cells count increased significantly from $171 / \mathrm{mm}^{3}[0-604]$ to $449 / \mathrm{mm}^{3}$ [130 - 964] between M0 and M12 ( $\left.<0.001\right)$, while the proportion of patients with CD4-T cells count below $200 / \mathrm{mm}^{3}$ decreased from $57 \%$ to $23 \%$ ( $\mathrm{p}=0.02$ ). Tolerability was good and no death was recorded during the 12-month's follow-up. Conclusions: These results show that the combination of OBT with the new ART can offer a salvage therapy in patients presenting a long-term history of virologic failures.
\end{abstract}

Keywords: Darunavir/Ritonavir; Etravirine; Raltegravir; HIV-1

\section{Introduction}

Human immunodeficiency virus type 1 (HIV-1) infection remains one of the most serious health problems in the world [1]. It is estimated that approximately 39 million people are living with HIV, with infection and death rates of around 4 million and 3 million per year, respectively [1]. Nowadays, the number of individuals infected with HIV-1 and the number of deaths due to acquired immunodeficiency syndrome (AIDS) continue to grow,

\footnotetext{
${ }^{*}$ Competing interests: The authors state that they have no conflicts of interest.

${ }^{\#}$ Corresponding author.
}

although communication and preventive tools are more accessible.

Although advances in the treatment and understanding of the disease have proven beneficial, there still remains a medical need for treatment of HIV infected patients. Currently, there are 22 drugs approved by the US Food and Drug Administration (FDA) for the treatment of HIV infection. These drugs are categorized according to their mode of action into five main groups: the nucleoside reverse transcriptase inhibitors (NRTI), the non nucleoside reverse transcriptase inhibitors (NNRTI), the protease inhibitors (PI), the integrase inhibitors (II), and entry inhibitors [2]. While highly active anti-retroviral therapy 
(HAART) is effective, it can fail to control HIV replication for several reasons such as lack of therapy adherence due to occurrence of sides effects affecting quality of life $[3,4]$, drug-drug interaction and loss of drug effectiveness caused by development of resistance, including multi-drug resistance and cross-resistance [5]. It is therefore essential to continue to develop new antiretroviral drugs with potency against drug resistant and non-resistant virus.

Patients with a long-term history of recurrent or chronic virologic failure on HART develop HIV-1 multiclasses drug resistance (MDR) reducing the efficiency of antiretroviral drugs. Consequently, no sustained virologic response can be obtained in such patients with drugs from classical classes. Before 2007, sequential use of available antiretrovirals could lead in such patients to sequential functional monotherapies, increasing multiresistance and cross-resistance. While such situations are today less and less frequent, especially in patients who initiated treatment after 2000, there is a small group of heavily-pretreated patients harbouring multi-drug HIV-1 with a history of poor tolerability and/or poor adherence. Simultaneous availability of new very active compounds offered the opportunity to construct potentially effective salvage regimens, with the hope to achieve immunovirologic control even in the patients previously considered in dead-end.

Darunavir/ritonavir (PI), Etravirine (NNRTI) and Raltegravir (II) represented new ART in their respective therapeutic classes which had shown antiviral activity against susceptible or multi-drug-resistant HIV [6-10]. Although phase 3 clinical studies with each of these individual new antiretrovirals have demonstrated their potential as salvage therapy, there is limited experience for the combination of these 3 antiretrovirals in patients with MDR HIV-1 [8-15].

We report our experience of 12 months follow-up of salvage therapy with darunavir/ritonavir and etravirine with or without raltegravir in a cohort of very heavily pretreated patients harbouring multi-drug resistant HIV-1.

\section{Patients and Methods}

Between January 2007 and June 2008, patients aged 18 years and older, followed in 2 HIV reference centres were included in this prospective analysis if 1) antiretroviral therapy initiation was prior to 1996; 2) they had long-term history of multiple virologic failures, defined by the persistence of detectable viral load (HIV-1 viral load $>1.60 \log _{10}$ HIV-1 RNA copies/ml) during ten years (1997-2008) with HART from the classical three classes of ART including NRTI, NNRTI and PI; 3) there was no possibility to construct a combination of 3 active antiretrovirals based on drugs available before 2006; and 4) if they received a salvage regimen containing at least 1 of the 3 new active agents among darunavir/ritonavir (600/100 mg twice daily), etravirine (200 mg twice daily) and raltegravir (400 mg twice daily) combined to optimized background therapy. HART therapy was defined as the combination of three or more antiretroviral drugs. The ART new drugs combination for patient treatment was selected in respect to patient history of multi-drugs resistance between 1997 and 2008. Drugs tolerability were assessed on the basis of clinical adverse events. The immuno-virological response, including CD4-T cells count and HIV-1 viral load evaluation were performed at baseline, before treatment initialization with new drugs (month zero: M0) and at M2, M4, M6 and M12. Effectiveness was measured as the percentage of patient acheving viral suppression (HIV-1 viral load $<1.60 \log _{10}$ HIV-1 RNA copies/ml) in intention-to-treat approach.

Data were entered in Excel, and statistical analysis was performed with Stata 11. Match-paired analyses were used to test differences in the distribution of outcomes and time points. For categorical variables Mc Nemar test was used and Wilcoxon signed-rank test was used for continuous variables. p value less than 0.05 was considered as significant.

\section{Results}

Among the 2350 patients followed in the 2 centres, 23 fullfilled study criteria: 21/23 (91\%) males, median age: 49 years (range: 19 - 65), CDC stage $C$ was present in $14 / 23$ (61\%) of the patients, the median year of HIV-1 detection was 1989 [1985-2002] and the median history of antiretroviral therapy was 14.5 years (range: 6 - 19).

At baseline (M0), the median time with detectable HIV-1 viral load ( $>1.60 \log _{10}$ HIV-1 RNA copies/ml) on antiretroviral therapy over the last 10 years (1997-2008) was 120 months (74 - 120), the median viral load was 4.3 $\log _{10}(1.98$ - 6) HIV-1 RNA copies/ml and the median CD4 count was $171 / \mathrm{mm}^{3}(0-604)$ (Table 1). Indeed, during these last 10 years, 18/23 (78\%) patients had less than 12 months of cumulated time with undetectable HIV viral load $\left(<1.60 \log _{10}\right.$ HIV-1 RNA copies/ml). For the 20/23 (87\%) patients with more than 10 years of antiretroviral therapy 74\% (17/23) had less than 6 consecutive months with undetectable HIV viral load. Moreover, the median number of prior anti-retrovirals used was 13 (6 16) and $80 \%$ of the patients received more than 12 of the 17 antiretroviral drugs available as of 2006 for which the HIV virus was resistant.

High active anti-retroviral treatment (HAART) combined with at least one of the three active antiretroviral drugs including darunavir/ritonavir, etravirine and/or raltegravir was used for patient treatment. Among them, 9/23 (39\%) patients received the three drugs, 13/23 (57\%) 
two drugs and 1/23 (4\%) received only one drug. The combinations prescribed were darunavir/ritonavir + etravirine + raltegravir [9/23 (39\%)], darunavir/ritonavir + raltegravir [8/23 (35\%)], darunavir/ritonavir + etravirine [5/23 (22\%)] and raltegravir [1/23 (4\%)].

Among the 23 patients included in the study 21, 18, 22 and 15 patients respectively had immuno-virologic tests and clinical examination at M2, M4, M6 and M12 (Table 1). During the 12 months of follow-up after prescription of the new drugs no patients developed new AIDS events and no death was recorded. Tolerability was good and none of the patients stopped their new antiretroviral combination for drug-related adverse event. Undetectable HIV viral load was observed in 0/23 (0\%), 19/22 (86\%) and 11/15 (73\%) patients at M0, M6 and M12 respectively (Table 1). The difference of the proportion of patient presenting undetectable viral load was statistically significant between M0 and M12 (Table 1, Figure 1(a), $\mathrm{p}=0.03)$. The median HIV-1 viral load decreased significantly from $4.32 \log _{10}$ RNA copies/ml at M0 to $1.69 \log _{10}$ RNA copies/ml at M6 and persist at M12 (Table $1, p<0.001$ ). The decrease in HIV-1 viral count was observed for 19/23 (83\%) patients between M0 and M12 (Figure 1(b)), while 3/23 (13\%) patients increased their HIV-1 viral load and 1/23 (4\%) had a persistently high level of HIV-1 viral load of more than 2.5 $\log _{10}$ RNA copies/ml (Figure 1(b)).

The median CD4 T-cell count increased significantly from $171 / \mathrm{mm}^{3}$ [5 - 528] at M0 to $449 / \mathrm{mm}^{3}$ [130 - 964] at M12 (p < 0.001) and the proportion of patients with T-CD4 cell count under $200 / \mathrm{mm}^{3}$ decreased from $57 \%$ at M0 to 23\% at the same period (Table 1, Figure 1(a), p = $0.02)$.

\section{Discussion}

The HAART has changed the natural history of HIV in- fection, reducing opportunistic infections and deaths [16]. However, treatment failures due to the emergence of HIV virus drug resistance are associated to a high risk of immuno-virological relapse. The difficult-to-treat-patients developing MDR HIV infection have high experience with antiretroviral therapy and no therapeutic option with all disposed antiretroviral drugs was possible. Recently, three molecules, darunavir/ritonavir, etravirine and raltégravir were proposed in the treatment of HIV infected patients [6-15]. In this study, we analyzed the efficiency of these new drugs combined to optimized background therapy during twelve months in patients with advanced MDR HIV-1 infection and treatment failures with the three classes of antiretroviral drugs.

According to our results, 4 patients showed partial virologic responses. From them, 3 patients (A, B and C) treated with the three new drugs or with darunavir plus etravirine had emerging viral loads during the follow-up and 1 patient (D) treated with raltegravir exhibited high levels of persistent viral load. These patients were poorly adherent to the ART and had a long-term history of non-adherence with bad treatment observance and discontinuous antiretroviral therapy. It is noteworthy that a persistently high level of HIV-1 viremia was shown in patient $\mathrm{D}$ receiving only raltegravir combined to optimized background therapy. This observation should be interpreted as a loss of viral sensitivity to raltegravir. The development of resistance to integrase inhibitors is a particular concern when raltegravir is by necessity used as monotherapy, or as in the present study, where this molecule was combined to no fully active drugs in the optimized background therapy [17-20]. The mutations associated with failure of raltegravir treatment affect integrase sensitivity to the virus inhibition and could therefore explain the viral replication in this patient [21]. Moreover, the extensive cross-resistance that exists between NNRTI has limited their use in resistant HIV in-

Table 1. Evolution of immunologic [CD4-T cells counts (cells/ $\left.\mathrm{mm}^{3}\right)$ ] and virologic [HIV-1 viral loads (HIV-1 RNA copies/ml)] parameters between month zero (M0), before new antiretroviral treatments and month twelve (M12). ${ }^{\mathrm{A}} \mathrm{p}=0.03$. ${ }^{\mathrm{B}} \mathrm{p}<0.001$. ${ }^{\mathrm{C}} \mathbf{p}<0.001,{ }^{\mathrm{D}} \mathbf{p}<0.02$.

\begin{tabular}{|c|c|c|c|c|c|}
\hline & Mo & M2 & M4 & M6 & M12 \\
\hline Staff & 23 & 21 & 18 & 22 & 15 \\
\hline $\begin{array}{l}\text { CD4-T cells count }\left(\text { cells } / \mathrm{mm}^{3}\right) \\
\text { - } \\
\text { - } \text { median } \\
\text { range }\end{array}$ & $\begin{array}{c}171^{\mathrm{C}} \\
(0-604)\end{array}$ & $\begin{array}{c}158 \\
(5-528)\end{array}$ & $\begin{array}{c}243 \\
(9-652)\end{array}$ & $\begin{array}{c}302 \\
(88-827)\end{array}$ & $\begin{array}{c}449^{\mathrm{C}} \\
(130-964)\end{array}$ \\
\hline $\begin{array}{c}\text { Patients with }<200 / \mathrm{mm}^{3} \text { CD4-T } \\
\text { cells count } \mathrm{N}(\%)\end{array}$ & $13 / 23(57 \%)^{\mathrm{D}}$ & 10/19 (53\%) & 7/16 (44\%) & 7/18 (39\%) & $3 / 13(23 \%)^{\mathrm{D}}$ \\
\hline $\begin{array}{ll} & \text { HIV-1 viral load }\left(\mathrm{c} / \mathrm{mm}^{3}\right) \\
\text { - } & \text { median } \\
\text { - } & \log _{10} \\
\text { - } & \text { range }\end{array}$ & $\begin{array}{c}21000 \\
4.32^{\mathrm{B}} \\
{[1.98-6]}\end{array}$ & $\begin{array}{c}69 \\
1.83 \\
{[0-4]}\end{array}$ & $\begin{array}{c}50 \\
1.69 \\
{[0-4.66]}\end{array}$ & $\begin{array}{c}50 \\
1.69 \\
{[0-3.84]}\end{array}$ & $\begin{array}{c}50 \\
1.69^{\mathrm{B}} \\
{[0-4.62]}\end{array}$ \\
\hline $\begin{array}{l}\text { Number of patients with } \\
\text { undetectable HIV-1 viral load (\%) }\end{array}$ & $0 / 23(0 \%)^{\mathrm{A}}$ & 15/21 (71\%) & 16/18 (89\%) & 19/22 (86\%) & $11 / 15(73 \%)^{A}$ \\
\hline
\end{tabular}



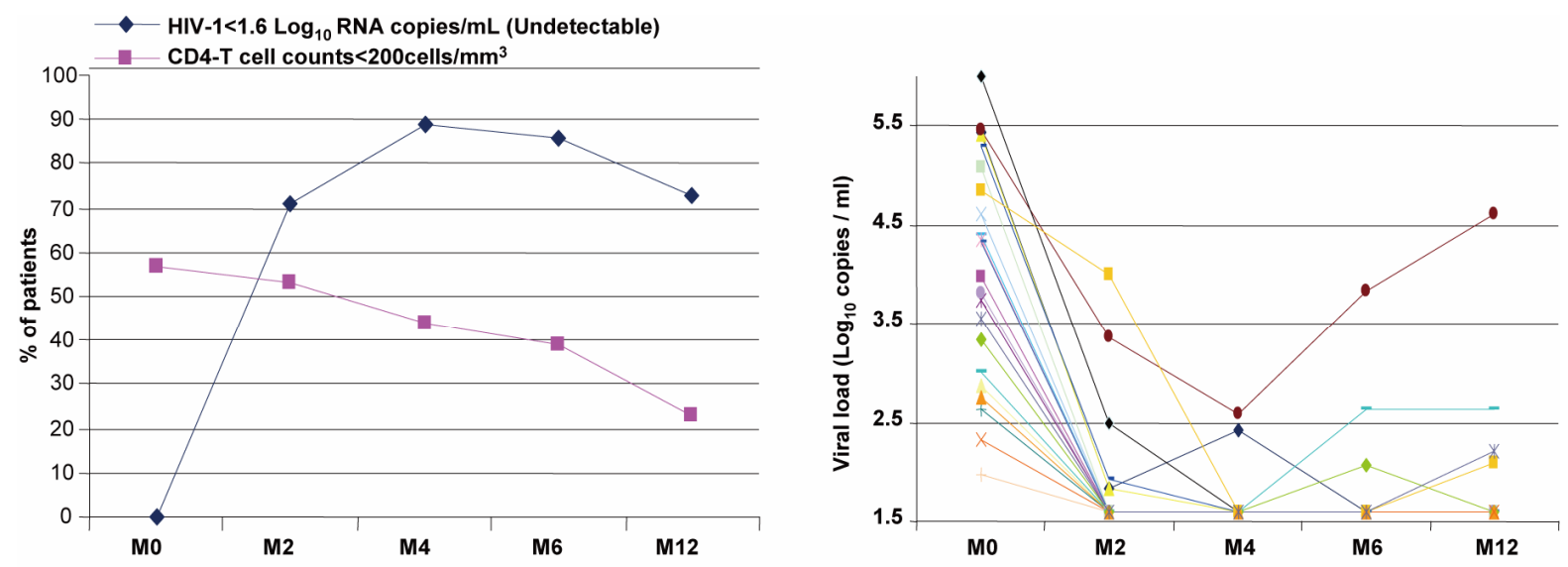

(a)

(b)

Figure 1. (a) Proportion of patients according to HIV viral load and CD4 T cell counts; (b) Individual HIV-1 viral loads evolution of the 23 patients between month zero (M0), before new antiretroviral treatment and month twelve (M12).

fections. Only etravirine has a genetic barrier to resistance compared to other NNRTI and could preserve antiviral activity against MDR HIV. This is in agreement with our result showing a decreasing viral load in patients $\mathrm{A}, \mathrm{B}$ and $\mathrm{C}$. In the same way, it has been shown that multiple mutations are required before there is a decrease in susceptibility to this drug, whereas only one mutation is needed to confer high-level resistance to the currently approved NNRTI [6,22]. However, darunavir/ ritonavir was found to maintain antiretroviral activity against HIV with PI mutations [23].

In the line of previous studies, ours observations argue strongly for the necessity to have a strategy using combined new drugs with optimized background therapy in order to avoid or limit the emergence of resistant HIV and to maintain long-term virologic response efficiency.

During the patient follow up the immunologic benefit was evidenced by increased CD4-T cell count and a decreased proportion of patients with CD4-T cells below to $200 / \mathrm{mm}^{3}$. When considering the patients history of the viral infection showing a HIV-1 viremia continuously detectable during 10 years, it is noteworthy that the viral load decreased in $86 \%$ patients after six months of new drug treatment. Indeed, the HIV-1 viral loads were reduced to less than $1.60 \log _{10}$ RNA copies/ml corresponding to rates reported among patients infected with virus sensitive to standard therapy. This viral load suppression was remarkable for patients infected with HIV-1 that has triple-class drug resistance and in whom therapy had failed previously. As observed in our study, the efficiency of darunavir, etravirine and raltegravir in MDR HIV-1 infected patients has been previously reported [8, 15]. It has been shown that in patients infected by MDR HIV-1 with few remaining treatment options, the opti- mized background therapy combined with these new molecules had a rapid and potent antiretroviral effect that was superior to the effect of optimized background therapy $[8,15]$. In our knowledge in respect to these finding the new antiretroviral treatments represent the single salvage therapeutic solutions in MDR HIV infected patient to date. The study of the tolerance to the new drugs and drug-drugs interactions needs be continued in order to determine with more precision adverse events, drug interaction activities against the virus and patient metabolism. However, early observations in studies evaluating salvage regimens with etravirine combined with darunavir suggest that there is no interaction between the two drugs and no in vitro antagonism was notified [2325].

\section{Conclusion}

These results which show a remarkable evolution of immuno-virologic responses in the most diffcult-to-treat patients who have a long-term history of chronic virologic failure would suggest that new active antiretrovirals drugs could offer a very successful salvage therapy for the suppression of multi-drug resistant HIV-1 infection. However, a longer follow-up is needed to assess the durability of such salvage regimens.

\section{Acknowledgements}

We thank Constantin Fesel who contributed in the writing and English correction of the manuscript.

\section{REFERENCES}

[1] UNAIDS (Geneva), "Report on the Global AIDS Epide- 
mic," Switzerland, 2006.

[2] Z. Temesgen, D. Warnke and M. J. Kasten, "Current Status of Antiretroviral Therapy," Expert Opinion on Pharmacotherapy, Vol. 7, No. 12, 2006, pp. 1541-1554. doi:10.1517/14656566.7.12.1541

[3] M. P. Carrieri, V. Villes, F. Raffi, C. Protopopescu, M. Preau, D. Salmon, A. Taieb, J. M. Lang, R. Verdon, G. Chene and B. Spire (APROCO-COPILOTE ANRS CO08 Study Group), "Self-Reported Side-Effects of AntiRetroviral Treatment among IDUs: A 7-Year Longitudinal Study (APROCO-COPILOTE COHORT ANRS CO8)," International Journal of Drug Policy, Vol. 18, No. 4, 2007, pp. 288-295. doi:10.1016/j.drugpo.2007.01.014

[4] C. Protopopescu, F. Marcellin, B. Spire, M. Préau, R. Verdon, D. Peyramond, F. Raffi, G. Chêne, C. Leport and M. P. Carrieri, "Health-Related Quality of Life in HIV-1Infected Patients on HAART: A Five-Years Longitudinal Analysis Accounting for Dropout in the APROCO-COPILOTE Cohort (ANRS CO-8)," Quality of Life Research, Vol. 16, No. 4, 2007, pp. 577-591. doi:10.1007/s11136-006-9151-7

[5] B. T. Røge, T. S. Barfod, O. Kirk, T. L. Katzenstein, N. Obel, H. Nielsen, C. Pedersen, L. R. Mathiesen, J. D. Lundgren and J. Gerstoft, "Resistance Profiles and Adherence at Primary Virological Failure in Three Different Highly Active Antiretroviral Therapy Regimens: Analysis of Failure Rates in a Randomized Study," HIV Medicine, Vol. 5, No. 5, 2004, pp. 344-351. doi:10.1111/j.1468-1293.2004.00233.x

[6] K. Andries, H. Azijn, T. Thielemans, D. Ludovici, M. Kukla, J. Heeres, P. Janssen, B. De Corte, J. Vingerhoets, R. Pauwels and M. P. de Béthune, "TMC125, a Novel Next-Generation Nonnucleoside Reverse Transcriptase Inhibitor Active against Nonnucleoside Reverse Transcriptase Inhibitor-Resistant Human Immunodeficiency Virus Type 1," Antimicrobial Agents and Chemotherapy, Vol. 48, No. 12, 2004, pp. 4680-4686. doi:10.1128/AAC.48.12.4680-4686.2004

[7] S. De Meyer, H. Azijn, D. Surleraux, D. Jochmans, A. Tahri, R. Pauwels, P. Wigerinck and M. P. de Béthune, "TMC114, a Novel Human Immunodeficiency Virus Type 1 Protease Inhibitor Active against Protease Inhibitor-Resistant Viruses, including a Broad Range of Clinical Isolates," Antimicrobial Agents and Chemotherapy, Vol. 49, No. 6, 2005, pp. 2314-2321. doi:10.1128/AAC.49.6.2314-2321.2005

[8] J. V. Madruga, P. Cahn, B. Grinsztejn, R. Haubrich, J. Lalezari, A. Mills, G. Pialoux, T. Wilkin, M. Peeters, J. Vingerhoets, G. de Smedt, L. Leopold, R. Trefiglio and B. Woodfall, "Efficacy and Safety of TMC125 (Etravirine) in Treatment-Experienced HIV-1-Infected Patients in DUET-1: 24-Week Results from a Randomised, DoubleBlind, Placebo-Controlled Trial," Lancet, Vol. 370, No. 9581, 2007, pp. 29-38. doi:10.1016/S0140-6736(07)61047-2

[9] A. Lazzarin, T. Campbell, B. Clotet, M. Johnson, C. Katlama, A. Moll, W. Towner, B. Trottier, M. Peeters, J. Vingerhoets, G. de Smedt, B. Baeten, G. Beets, R. Sinha and B. Woodfall (DUET-2 Study Group), "Efficacy and
Safety of TMC125 (Etravirine) in Treatment-Experienced HIV-1-Infected Patients in DUET-2: 24-Week Results from a Randomised, Double-Blind, Placebo-Controlled Trial,” Lancet, Vol. 370, No. 9581, 2007, pp. 39-48. doi:10.1016/S0140-6736(07)61048-4

[10] R. T. Steigbigel, D. A. Cooper, P. N. Kumar, J. E. Eron, M. Schechter, M. Markowitz, M. R. Loutfy, J. L. Lennox, J. M. Gatell, J. K. Rockstroh, C. Katlama, P. Yeni, A. Lazzarin, B. Clotet, J. Zhao, J. Chen, D. M. Ryan, R. R. Rhodes, J. A. Killar, L. R. Gilde, K. M. Strohmaier, A. R. Meibohm, M. D. Miller, D. J. Hazuda, M. L. Nessly, M. J. DiNubile, R. D. Isaacs, B. Y. Nguyen and H. Teppler (BENCHMRK Study Teams), "Raltegravir with Optimized Background Therapy for Resistant HIV-1 Infection,” New England Journal of Medicine, Vol. 359, 2008, pp. 339-354. doi:10.1056/NEJMoa0708975

[11] M. Boffito, A. Winston, A. Jackson, C. Fletcher, A. Pozniak, M. Nelson, G. Moyle, I. Tolowinska, R. Hoetelmans, D. Miralles and B. Gazzard, "Pharmacokinetics and Antiretroviral Response to Darunavir/Ritonavir and Etravirine Combination in Patients with High-Level Viral Resistance,” AIDS, Vol. 21, No. 11, 2007, pp. 1449-1455. doi:10.1097/QAD.0b013e3282170ab1

[12] A. Di Biagio, B. Bruzzone, R. Rosso, O. Vigano, G. Icardi, C. Viscoli and S. Rusconi, "Successful Rescue Therapy with Raltegravir (MK-0518) and Etravirine (TMC125) in an HIV-Infected Patient Failing All Four Classes of Antiretroviral Drugs," AIDS Patient Care and STDS, Vol. 22, No. 5, 2008, pp. 355-357. doi:10.1089/apc.2007.0215

[13] A. M. Audelin, A. M. Lebech, A. B. Petersen and L. B. Jorgensen, "Follow-Up of a Multi-Drug Resistant HIV-1 Infected Patient Successfully Treated with Darunavir and Etravirine,” Journal of Medical Virology, Vol. 80, No. 8, 2008, pp. 1319-1321. doi:10.1002/jmv.21226

[14] Y. Yazdanpanah, C. Fagard, D. Descamps, A. M. Taburet, C. Colin, B. Roquebert, C. Katlama, G. Pialoux, C. Jacomet, C. Piketty, D. Bollens, J. M. Molina and G. Chêne (ANRS 139 TRIO Trial Group), "High Rate of Virologic Suppression with Raltegravir plus Etravirine and Darunavir/Ritonavir among Treatment-Experienced Patients Infected with Multidrug-Resistant HIV: Results of the ANRS 139 TRIO Trial," Clinical Infectious Diseases, Vol. 49, No. 9, 2009, pp. 1441-1449. doi:10.1086/630210

[15] A. Imaz, S. V. del Saz, M. A. Ribas, A Curran, E. Caballero, V. Falcó, M. Crespo, I. Ocaña, M. Diaz, E. R. de Gopegui, M. Riera and E. Ribera, "Raltegravir, Etravirine, and Ritonavir-Boosted Darunavir: A Safe and Successful Rescue Regimen for Multidrug-Resistant HIV-1 Infection," Journal of Acquired Immune Deficiency Syndromes, Vol. 52, No. 3, 2009, pp. 382-386. doi:10.1097/QAI.0b013e3181b17f53

[16] J. A. Sterne, M. A. Hernán, B. Ledergerber, K. Tilling, R. Weber, P. Sendi, M. Rickenbach, J. M. Robins and M. Egger, "Swiss HIV Cohort Study: Long-Term Effectiveness of Potent Antiretroviral Therapy in Preventing AIDS and Death: A Prospective Cohort Study," Lancet, Vol. 366, No. 9483, 2005, pp. 378-384. doi:10.1016/S0140-6736(05)67022-5 
[17] M. A. Kolber, R. E. Campo and G. M. Dickinson, "Development of Anti-Retroviral Resistance of HIV-1 Infected Individuals on Therapy: Is It Inevitable?” IUBMB Life, Vol. 56, No. 6, 2004, pp. 301-307. doi:10.1080/1521-6540400000843

[18] Z. Temesgen, F. Cainelli, E. M. Poeschla, S. A. Vlahakis and S. Vento, "Approach to Salvage Antiretroviral Therapy in Heavily Antiretroviral-Experienced HIV-Positive Adults,” Lancet Infectious Diseases, Vol. 6, No. 8, 2006, pp. 496-507. doi:10.1016/S1473-3099(06)70550-3

[19] D. A. Cooper, R. T. Steigbigel, J. M. Gatell, J. K. Rockstroh, C. Katlama, P. Yeni, A. Lazzarin, B. Clotet, P. N. Kumar, J. E. Eron, M. Schechter, M. Markowitz, M. R. Loutfy, J. L. Lennox, J. Zhao, J. Chen, D. M. Ryan, R. R. Rhodes, J. A. Killar, L. R. Gilde, K. M. Strohmaier, A. R. Meibohm, M. D. Miller, D. J. Hazuda, M. L. Nessly, M. J. DiNubile, R. D. Isaacs, H. Teppler and B. Y. Nguyen (BENCHMRK Study Teams), "Subgroup and Resistance Analyses of Raltegravir for Resistant HIV-1 Infection," New England Journal of Medicine, Vol. 359, 2008, pp. 355-365. doi:10.1056/NEJMoa0708978

[20] E. Poveda, C. de Mendoza, L. Martin-Carbonero, A. Corral, V. Briz, J. González-Lahoz and V. Soriano, "Prevalence of Darunavir Resistance Mutations in HIV-1Infected Patients Failing Other Protease Inhibitors," Journal of Antimicrobial Chemotherapy, Vol. 60, No. 4, 2007, pp. 885-888. doi:10.1093/jac/dkm276

[21] I. Malet, O. Delelis, M. A. Valantin, B. Montes, C. Soulie, M. Wirden, L. Tchertanov, G. Peytavin, J. Reynes, J. F. Mouscadet, C. Katlama, V. Calvez and A. G. Marcelin,
"Mutations Associated with Failure of Raltegravir Treatment Affect Integrase Sensitivity to the Inhibitor in $\mathrm{Vi}$ tro," Antimicrobial Agents and Chemotherapy, Vol. 52, No. 4, 2008, pp. 1351-1358. doi:10.1128/AAC.01228-07

[22] E. Poveda, E. Vispo, T. Pattery, C. de Mendoza, J. Villacian and V. Soriano, "Impact of Baseline Protease Genotype and Phenotype on the Response to Darunavir Outside Clinical Trials,” Journal of Antimicrobial Chemotherapy, Vol. 60, No. 6, 2007, pp. 1411-1413. doi:10.1093/jac/dkm367

[23] C. McCoy, "Darunavir: A Nonpeptidic Antiretroviral Protease Inhibitor," Clinical Therapeutics, Vol. 29, No. 8, 2007, pp. 1559-1576. doi:10.1016/j.clinthera.2007.08.016

[24] M. Boffito, A. Winston, A. Jackson, C. Fletcher, A. Pozniak, M. Nelson, G. Moyle, I. Tolowinska, R. Hoetelmans, D. Miralles and B. Gazzard, "Pharmacokinetics and Antiretroviral Response to Darunavir/Ritonavir and Etravirine Combination in Patients with High-Level Viral Resistance,” AIDS, Vol. 21, No. 11, 2007, pp. 1449-1455. doi:10.1097/QAD.0b013e3282170ab1

[25] J. Montaner, P. Yeni, N. N. Clumeck, G. Fatkenheuer, J. Gatell, P. Hay, E. Seminari, M. P. Peeters, M. SchöllerGyüre, M. Simonts and B. Woodfall (TMC125-C203 Study Group), "Safety, Tolerability, and Preliminary Efficacy of 48 Weeks of Etravirine Therapy in a Phase IIb Dose-Ranging Study Involving Treatment-Experienced Patients with HIV-1 Infection,” Clinical Infectious Diseases, Vol. 47, No. 7, 2008, pp. 969-978. $\underline{\text { doi:10.1086/591705 }}$ 